\title{
Molecular evaluation of herbal compounds as potent inhibitors of acetylcholinesterase for the treatment of Alzheimer's disease
}

\author{
YAN-XIU CHEN ${ }^{1}$, GUAN-ZENG LI $^{1}$, BIN ZHANG $^{2}$, ZHANG-YONG XIA $^{1}$ and MEI ZHANG ${ }^{3}$ \\ ${ }^{1}$ Department of Neurology, Liaocheng People's Hospital and Liaocheng Clinical School of Taishan Medical University; \\ ${ }^{2}$ Department of Neurology, The 3rd People's Hospital of Liaocheng, Liaocheng, Shandong 252000; \\ ${ }^{3}$ Department of Neurology, The 5th People's Hospital of Wuhan, Wuhan, Hubei 430050, P.R. China
}

Received June 15, 2015; Accepted April 15, 2016

DOI: $10.3892 / \mathrm{mmr} .2016 .5244$

\begin{abstract}
Alzheimer's disease (AD) is a progressive disease and the predominant cause of dementia. Common symptoms include short-term memory loss, and confusion with time and place. Individuals with AD depend on their caregivers for assistance, and may pose a burden to them. The acetylcholinesterase (AChE) enzyme is a key target in AD and inhibition of this enzyme may be a promising strategy in the drug discovery process. In the present study, an inhibitory assay was carried out against AChE using total alkaloidal plants and herbal extracts commonly available in vegetable markets. Subsequently, molecular docking simulation analyses of the bioactive compounds present in the plants were conducted, as well as a protein-ligand interaction analysis. The stability of the docked protein-ligand complex was assessed by $20 \mathrm{~ns}$ molecular dynamics simulation. The inhibitory assay demonstrated that Uncaria rhynchophylla and Portulaca oleracea were able to inhibit AChE. In addition, molecular docking simulation analyses indicated that catechin present in Uncaria rhynchophylla, and dopamine and norepinephrine present in Portulaca oleracea, had the best docking scores and interaction energy. In conclusion, catechin in Uncaria rhynchophylla, and dopamine and norepinephrine in Portulaca oleracea may be used to treat AD.
\end{abstract}

\section{Introduction}

Alzheimer's disease (AD) is a chronic neurodegenerative disease, which accounts for the majority of dementia cases (1). Common symptoms of AD include short-term memory loss, disorientation, loss of motivation, mood swings and behavioral issues $(1,2)$. Patients with AD often withdraw from family and society as their condition declines $(3,4)$.

Correspondence to: Dr Mei Zhang, Department of Neurology, The 5th People's Hospital of Wuhan, 122 Xianzheng Street, Wuhan, Hubei 430050, P.R. China

E-mail: meizhang918@gmail.com

Key words: Alzheimer's disease, acetylcholinesterase, molecular docking, molecular dynamics
The cause of AD is not fully understood (1), and researchers have hypothesized that $\sim 70 \%$ of the risk is due to genetic factors (4), followed by other factors, including head injuries, depression or hypertension (4-7). Patients with AD rely on caregivers for assistance, and in certain cases they may pose a burden to them (6). In developed countries, AD is considered to be one of the most financially challenging diseases (8-11). The underlying mechanisms of AD are not fully known and the majority of available drug therapies are based on the cholinergic hypothesis (12). The cholinergic hypothesis proposes that $\mathrm{AD}$ results from reduced synthesis of the neurotransmitter acetylcholine (ACh) (12). Houghton et al (13) indicated that inhibiting the enzyme acetylcholinesterase (AChE), which breaks down ACh, is a promising strategy for treating patients with $\mathrm{AD}$. There are alternative hypotheses, such as the amyloid (14) and tau (15) hypotheses; however, AChE is a favorable enzyme target for numerous researchers. Furthermore, AChE has garnered more attention regarding its screening potential, and the identification of AChE novel inhibitors from various natural products, including plants and herbal extracts.

The enzyme AChE is a hydrolase of the carboxylesterase family, which hydrolyzes the neurotransmitter ACh $(16,17)$. It is primarily present in the neuromuscular junctions and cholinergic brain synapses, assisting in the termination of synaptic transmissions. It belongs to the carboxylesterase family of enzymes $(18,19)$. During neurotransmission, ACh is released from the nerve into the synaptic cleft where it binds to ACh receptors on the post-synaptic membrane, relaying the signal from the nerve (20). AChE is located on the post-synaptic membrane and terminates the signal transmission by hydrolyzing Ach (21). The liberated choline is then taken up by the pre-synaptic nerve and $\mathrm{ACh}$ is synthesized by combining with acetyl-CoA through the action of choline acetyltransferase (22).

The present study performed an inhibitory assay to determine the inhibitory activity of certain plant extracts against human AChE. In addition, computational research employing virtual screening of the compounds present in the plant extracts and AChE retrieved from the Protein Data Bank (PDB ID: 4PQE) was conducted, using the molecular docking simulation protocol. Subsequently, a protein-ligand interaction analysis was performed with $20 \mathrm{~ns}$ molecular dynamics (MD) simulation. 
Table I. Inhibitory activity of the total alkaloidal extracts (100 $\mu \mathrm{g} / \mathrm{ml}$ final concentration) against AChE.

\begin{tabular}{lllll}
\hline SN & \multicolumn{1}{c}{ Scientific name } & Parts used & Yield & AChE inhibition (\%) \\
\hline 1 & Allium sativum & Bulb & 0.44 & 33.8 \\
2 & Areca catechu & Fruit & 0.66 & 19.3 \\
3 & Camellia sinensis & Leaves & 0.51 & 40.2 \\
4 & Curcuma longa & Root & 0.27 & 35.8 \\
5 & Lobelia chinensis & Whole plant & 0.21 & 28.2 \\
6 & Nelumbo nucifera & Leaves & 0.34 & 76.5 \\
7 & Portulaca oleracea & Stem & 0.24 & 74.2 \\
8 & Uncaria rhynchophylla & Stem & 0.41 & 78.4 \\
9 & Zingiber officinale & Root & 0.43 & 60.5 \\
\hline
\end{tabular}

AChE, acetylcholinesterase; $\mathrm{SN}$, serial number.

Table II. Compounds associated with the herbal plants and their NCBI Pubchem ID.

\begin{tabular}{|c|c|c|c|}
\hline $\mathrm{SN}$ & Plant & Chemical composition & Pubchem ID \\
\hline 1 & Nelumbo nucifera & $\begin{array}{l}\text { Miquelianin } \\
\text { Coclaurine } \\
\text { Higenamine } \\
\text { Nuciferine }\end{array}$ & $\begin{array}{l}\text { CID } 5274585 \\
\text { CID } 160487 \\
\text { CID } 114840 \\
\text { CID } 3108374\end{array}$ \\
\hline 2 & Portulaca oleracea & $\begin{array}{l}\text { Norepinephrine } \\
\text { Dopamine } \\
\text { L-DOPA }\end{array}$ & $\begin{array}{l}\text { CID } 439260 \\
\text { CID } 681 \\
\text { CID } 6047\end{array}$ \\
\hline 3 & Uncaria rhynchophylla & $\begin{array}{l}\text { Catechin } \\
\text { Rhynchophylline }\end{array}$ & $\begin{array}{l}\text { CID } 9064 \\
\text { CID } 3033948\end{array}$ \\
\hline 4 & Areca catechu & $\begin{array}{l}\text { Arecaidine } \\
\text { Arecoline }\end{array}$ & $\begin{array}{l}\text { CID } 10355 \\
\text { CID } 2230\end{array}$ \\
\hline 5 & Lobelia chinensis & $\begin{array}{l}\text { Lobeline } \\
\text { Lobelanine } \\
\text { Lobelanidine }\end{array}$ & $\begin{array}{l}\text { CID } 101616 \\
\text { CID } 442647 \\
\text { CID } 96946\end{array}$ \\
\hline 6 & Curcuma longa & Curcumin & CID 969516 \\
\hline 7 & Zingiber officinale & $\begin{array}{l}\text { Zingerone } \\
\text { Shogaol } \\
\text { Gingerol }\end{array}$ & $\begin{array}{l}\text { CID } 31211 \\
\text { CID } 5281794 \\
\text { CID } 442793\end{array}$ \\
\hline 8 & Allium sativum & $\begin{array}{l}\text { Allicin } \\
\text { Ajoene }\end{array}$ & $\begin{array}{l}\text { CID } 65036 \\
\text { CID } 5386591\end{array}$ \\
\hline 9 & Camellia sinensis & Gallocatechol & CID 65084 \\
\hline
\end{tabular}

NCBI, National Center for Biotechnology Information; SN, serial number; L-DOPA, L-3,4-dihydroxyphenylalanine.

\section{Materials and methods}

AChE inhibitory assay. The following plant samples with medicinal properties were collected: Allium sativum, Areca catechu, Camellia sinensis, Curcuma longa, Lobelia chinensis, Nelumbo nucifera, Portulaca oleracea, Uncaria rhynchophylla and Zingiber officinale. The majority of the collected samples are commonly available in vegetable and herbal medicine markets. Approximately $120 \mathrm{~g}$ of each of the plant samples was crushed to a powder using a pestle and mortar. Each of the samples was then treated with $95 \%$ ethanol and was refluxed for $2 \mathrm{~h}$ to collect the alcohol extract. The extract was further evaporated, air-dried and suspended in deionized water. The $\mathrm{pH}$ of the suspension was adjusted to 2.0. The aqueous solution from the alkaloidal extracts, which is acidic in nature, was filtered following an overnight incubation, the $\mathrm{pH}$ was adjusted to 10.0 and the extract was obtained using chloroform. The layers of chloroform were evaporated and air dried. The final alkaloidal extracts obtained were used to conduct the AChE inhibitory assay, which was purchased from 
Table III. Molecular docking scores of the compounds.

\begin{tabular}{llccrr}
\hline Ligand & \multicolumn{1}{c}{ Source } & Rerank score & MolDock score & Interaction & HBond \\
\hline CID 9064 & Uncaria rhynchophylla & -67.43 & -91.57 & -114.847 & -11.47 \\
CID 681 & Portulaca oleracea & -64.76 & -84.07 & -86.940 & -12.38 \\
CID 439260 & Portulaca oleracea & -60.40 & -81.88 & -83.460 & -12.14 \\
CID 31211 & Zingiber officinale & -59.39 & -46.98 & -48.230 & -3.87 \\
CID 65084 & Camellia sinensis & -53.40 & -71.24 & -78.860 & -9.88 \\
CID 6047 & Portulaca oleracea & -50.14 & -36.84 & -32.170 & -9.71 \\
CID 65036 & Allium sativum & -49.10 & -29.47 & -26.750 & -2.02 \\
CID 442793 & Zingiber officinale & -48.79 & -72.86 & -73.050 & -2.16 \\
CID 114840 & Nelumbo nucifera & -45.15 & -47.37 & -55.850 & -8.94 \\
CID 160487 & Nelumbo nucifera & -43.02 & -51.27 & -59.170 & -5.89 \\
CID 5386591 & Allium sativum & -40.22 & -10.84 & -6.720 & -1.65 \\
CID 5281794 & Zingiber officinale & -39.29 & -73.70 & -67.630 & -7.49 \\
\hline
\end{tabular}

MolDock, molecular docking; HBond, hydrogen bond.
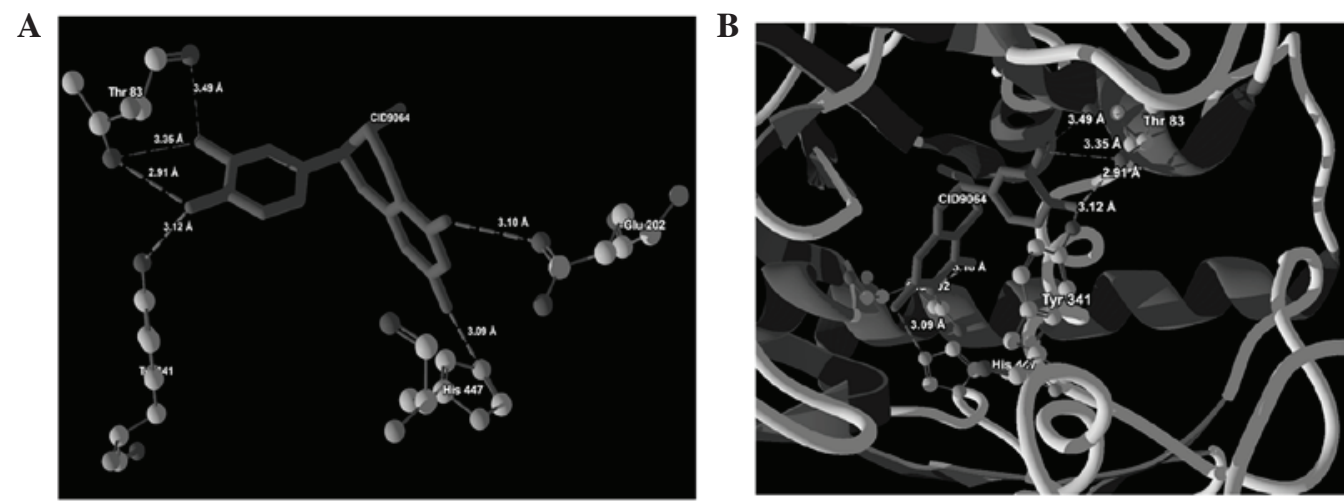

Figure 1. (A) Binding mode of CID9064 at the active site region of AChE. (B) Secondary structure depicting the strong molecular interactions formed between CID681 and Thr83, Glu202, Thr341 and His447 residues of AChE. AChE, acetylcholinesterase.

Sigma-Aldrich (St. Louis, MO, USA). The AChE inhibitory assay was performed according to the protocol developed by Ellman et al (23) with slight modifications. Briefly, a mixture containing $100 \mu \mathrm{l} 0.1 \mathrm{M} \mathrm{NaH}_{2} \mathrm{PO}_{4}$ (pH 8.0), $25 \mu \mathrm{l}$ plant extract solution $(1 \mathrm{mg} / \mathrm{ml})$ and $20 \mu \mathrm{l}$ AChE enzyme $(0.20 \mathrm{U} / \mathrm{ml})$ was incubated for $30 \mathrm{~min}$ at $4^{\circ} \mathrm{C}$. Subsequently, $\sim 15 \mu 10.01 \mathrm{M}$ 5,5'-dithiobis(2-nitrobenzoic acid) mixed with $10 \mu 10.05 \mathrm{M}$ acetylthiocholine iodide was incubated with the mixture at $37^{\circ} \mathrm{C}$ for $30 \mathrm{~min}$. The optical density of the final solution was measured at $405 \mathrm{~nm}$ (ELC800 Absorbance Microplate Reader; BioTek Instruments, Inc., Winooski, VT, USA), and enzyme activity was calculated by comparing the reaction rate of the samples relative to a blank solution. The percentage of inhibitory activity was calculated by subtracting the enzyme activity percentage from $100 \%$.

Molecular docking. The molecular docking simulation was performed using the Molegro Virtual Docker 5.0 (CLC Bio, Aarhus, Denmark). Briefly, the 2D structures of the compounds present in the plant samples were retrieved from the National Center for Biotechnology Information (NCBI) PubChem database (https://pubchem.ncbi.nlm.nih.gov). Their geometries were optimized using the MM2 force field and were converted to a 3D format (sybyl mol2 file format). AChE retrieved from the PDB (ID: 4PQE) was then loaded into the Molegro Virtual Docker. The bind site was set having a sphere of $15 \AA$ radius and the following coordinates: X, -27.90; Y, 22.91; Z,-10.18.

For the molecular docking simulation, the bonds of all the compounds were set flexible, and for the protein the residues in the binding site were set flexible with a tolerance of 1.0 and strength of 0.80 . The side chain and torsional degrees of freedom for the flexible residues and ligands were subjected to 2,000 steps of energy minimization. Flexible molecular docking simulations were performed setting the MolDock Grid scoring function (24) with a grid resolution of $0.30 \AA$. The search algorithm was set for MolDock SE with 20 runs for each compound, with a maximum of 1,500 iterations and population size of 50 . The in-depth molecular interaction was inspected using a ligand energy inspector. The ligand energy inspector evaluates the energy interactions for a given docked ligand with the interacting amino acids. In the present study, the in-depth molecular interaction was inspected using a ligand energy inspector. The ligand energy inspector evaluates the energy interactions for a given docked ligand with the interacting amino acids. 
Table IV. Molecular interaction analysis of the top hits.

\begin{tabular}{|c|c|c|c|c|}
\hline $\mathrm{SN}$ & Ligand & Protein-ligand & $\begin{array}{c}\text { Interaction } \\
\text { energy }(\mathrm{kJ} / \mathrm{mol})\end{array}$ & $\begin{array}{c}\text { Interaction } \\
\text { distance }(\AA)\end{array}$ \\
\hline \multirow[t]{6}{*}{1} & \multirow[t]{6}{*}{ CID9064 } & Thr83(OG1)-O(5) & -2.50 & 2.91 \\
\hline & & Thr83(OG1)-O(4) & -1.26 & 3.35 \\
\hline & & Thr83(O)-O(4) & -0.55 & 3.49 \\
\hline & & Thr341(OH)-O(5) & -2.40 & 3.12 \\
\hline & & His447(NE2)-O(3) & -2.50 & 3.09 \\
\hline & & Glu202(OE1)-O(2) & -2.50 & 3.10 \\
\hline \multirow[t]{8}{*}{2} & \multirow[t]{8}{*}{ CID681 } & Asn87(OD1)-N(2) & -0.57 & 3.49 \\
\hline & & Gln71(OE1)-N(2) & -1.61 & 3.28 \\
\hline & & Tyr72(O)-N(2) & -2.50 & 2.96 \\
\hline & & Tyr341(OH)-O(0) & -2.50 & 2.88 \\
\hline & & Asp74(OD2)-O(0) & -2.20 & 3.16 \\
\hline & & Asp74(OD2)-O(1) & -1.40 & 3.32 \\
\hline & & Tyr341(OH)-O(1) & -0.55 & 2.37 \\
\hline & & Thr83(OG1)-O(1) & -2.50 & 2.90 \\
\hline \multirow[t]{7}{*}{3} & \multirow[t]{7}{*}{ CID439260 } & Ser125(OG)-O(2) & -2.00 & 3.21 \\
\hline & & $\operatorname{Trp} 86(\mathrm{O})-\mathrm{O}(2)$ & -1.10 & 3.38 \\
\hline & & Gly120(O)-O(1) & -1.75 & 3.25 \\
\hline & & Tyr133(OH)-O(1) & -2.20 & 2.56 \\
\hline & & His447(NE2)-N(3) & -2.50 & 2.65 \\
\hline & & Glu202(OE2)-N(3) & -0.14 & 3.27 \\
\hline & & Glu202(OE1)-N(3) & -2.50 & 3.10 \\
\hline \multirow[t]{2}{*}{4} & \multirow[t]{2}{*}{ CID31211 } & Tyr337(OH)-O(0) & -2.50 & 2.78 \\
\hline & & His447(O)-O(1) & -1.37 & 2.46 \\
\hline \multirow[t]{6}{*}{5} & \multirow[t]{6}{*}{ CID65084 } & Thr83(OG1)-O(6) & -2.50 & 2.97 \\
\hline & & Thr83(O-O(6) & -0.36 & 3.46 \\
\hline & & $\operatorname{Trp} 86(0)-\mathrm{O}(1)$ & -0.24 & 3.32 \\
\hline & & Glu202(OE1)-O(2) & -2.50 & 3.10 \\
\hline & & Ser303(OG1)-O(3) & -1.68 & 3.26 \\
\hline & & His447(NE2)-O(3) & -2.50 & 2.60 \\
\hline \multirow[t]{5}{*}{6} & \multirow[t]{5}{*}{ CID6047 } & His447(NE2)-N(4) & -2.50 & 3.10 \\
\hline & & Glu202(OE2)-N(4) & -2.50 & 2.60 \\
\hline & & His447(O)-O(1) & -2.50 & 2.73 \\
\hline & & Ser125(OG)-O(2) & -1.31 & 2.46 \\
\hline & & Gly120(O)-O(0) & -0.90 & 2.89 \\
\hline
\end{tabular}

SN, serial number.

MD simulation. MD simulations were performed using the GROMACS 5.0 (Royal Institute of Technology, Stockholm, Sweden; and Uppsala University, Uppsala, Sweden) installed in Ubuntu Linux 14.0 LTS Intel i5 processor with the standard GROMOS96 43a1 force field (25). MD simulation was performed for the docked protein-ligand complexes and $\mathrm{AChE}$ (PDB ID: 4PQE). For the protein and the protein-ligand docked complexes, initially, the system was immersed in a cubic water box and the energy of the complexes was minimized using the steepest descent approach. Following energy minimization, the systems were equilibrated for 100 ps with NVT (number of particles, volume and temperature; canonical) and NPT (number of particles, temperature and pressure; isothermal-isobaric) ensemble equilibration protocol for $\sim 5,000$ steps. Finally, the equilibrated systems were run for $20 \mathrm{~ns}$ of MD simulation production under a constant number of particles at $310 \mathrm{~K}$ and 1 bar pressure. The trajectory was analyzed and a graph was plotted for the root mean square deviation (RMSD) backbone of $\mathrm{AChE}$ and the AChE-ligand complexes.

\section{Results}

The AChE inhibitory activities of the plant extracts are presented in Table I. Total alkaloidal extracts from Nelumbo nucifera, Uncaria rhynchophylla and Portulaca oleracea exhibited 76.5, 78.4 and $74.2 \%$ inhibition against AChE, respectively (Table I). 
A

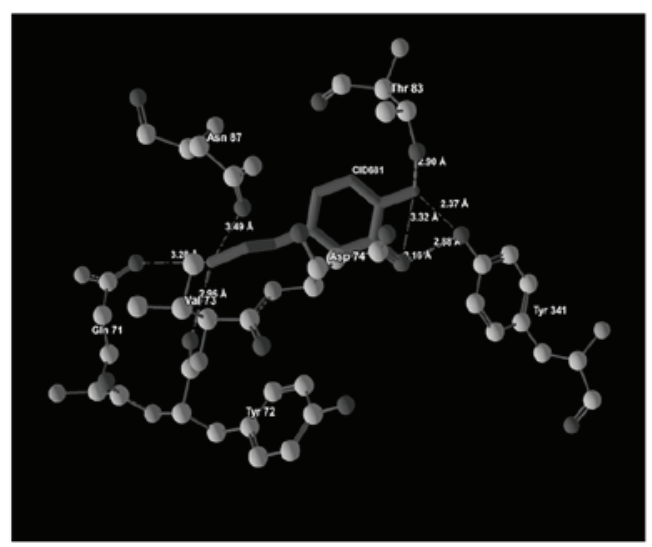

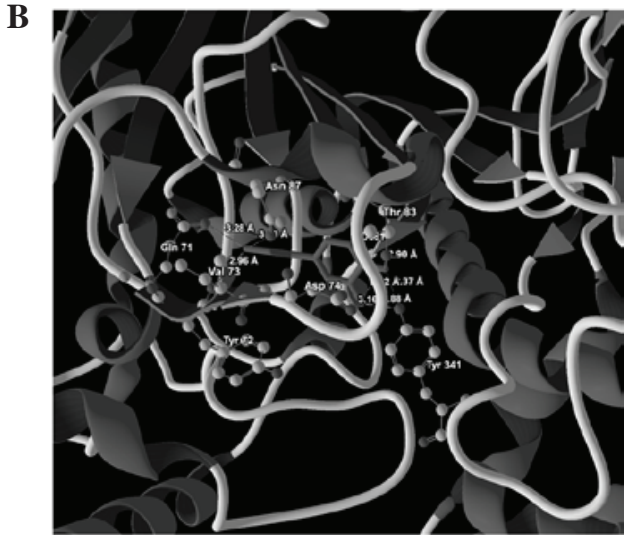

Figure 2. (A) Binding mode of CID681 at the active site region of AChE. (B) Secondary structure depicting the strong molecular interactions formed between CID681 and Tyr71, Gln71, Asp74, Thr83, Asn87, Tyr341 residues of AChE AChE, acetylcholinesterase.

A

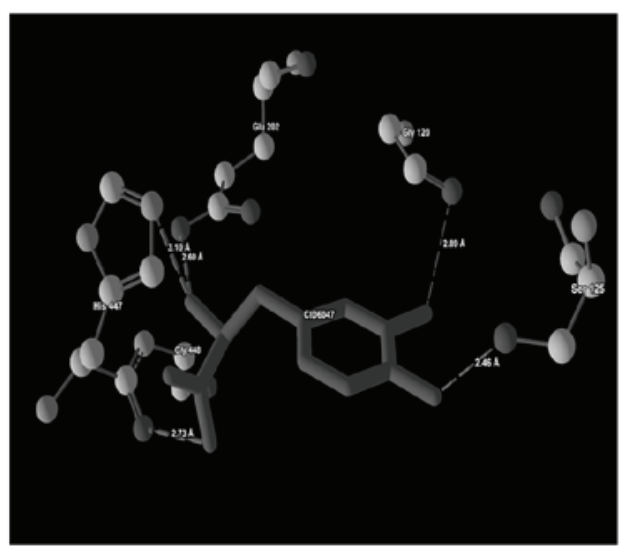

B

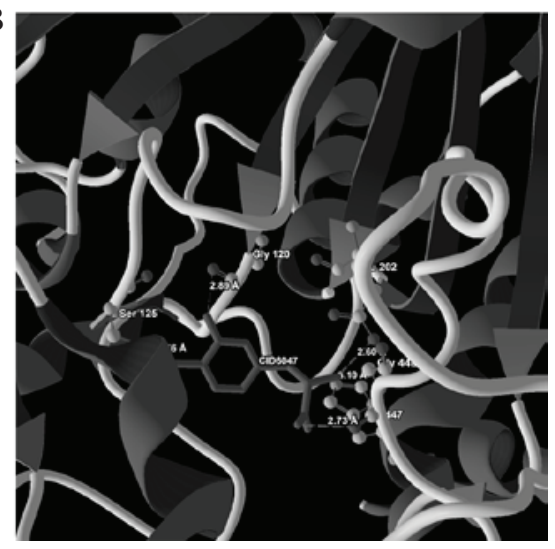

Figure 3. (A) Binding mode of CID6047 at the active site region of AChE. (B) Secondary structure depicting the strong molecular interactions formed between CID6047 and Trp86, Gly120, Ser125, Tyr133, Glu202, His447 residues of AChE. AChE, acetylcholinesterase.

A

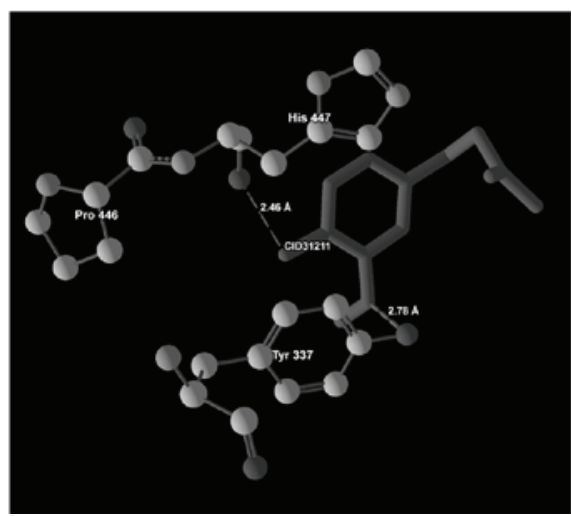

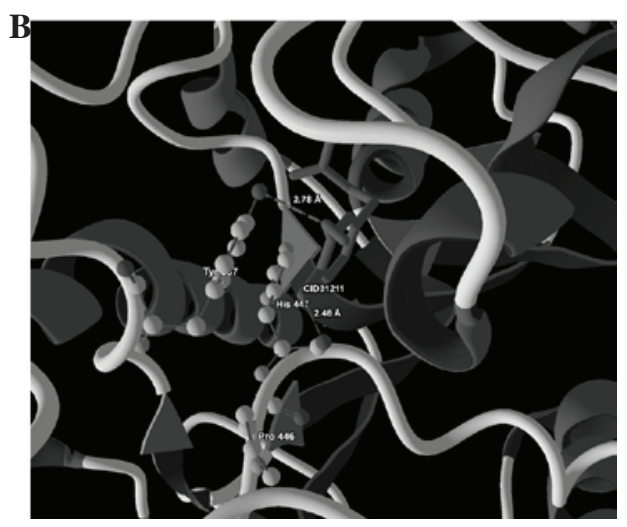

Figure 4. (A) Binding mode of CID31211 at the active site region of AChE. (B) Secondary structure depicting the strong molecular interactions formed between CID31211 and Tyr337, His447 residues of AChE. AChE, acetylcholinesterase.

The compounds present in the herbal plants were retrieved from the NCBI PubChem database, and are presented in Table II. The molecular docking scores of the bioactive compounds present in the herbal plants against AChE are shown in Table III. The scores and results were based on the Rerank and MolDock scores, and interaction energy (24). Rerank Score, MolDock Score and Interaction Energy are measure based on the energy parameters E inter (steric, van der Waals, hydrogen bonding and electrostatic) between the ligand and the protein, and E intra (torsion, SP2, hydrogen bonding, van der Waals and electrostatic) (24). These energy terms are generated by the MolDock SE algorithm and based on the most stable E inter and E intra; the compounds were ranked accordingly. The results of the ligand-protein interaction analyses of the top docked compounds against AChE (PDB ID: 4PQE) are presented in Table IV. Images depicting the molecular interactions for the 

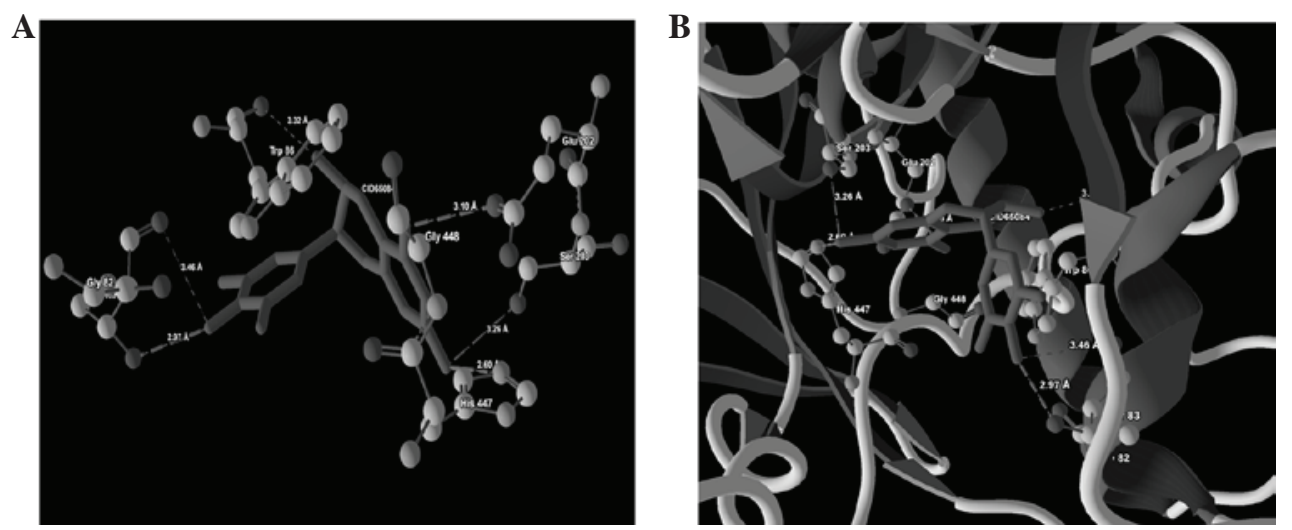

Figure 5. (A) Binding mode of CID65084 at the active site region of AChE. (B) Secondary structure depicting the strong molecular interactions formed between CID65084 and Thr83, Trp86, Glu202, Ser303, His447 residues of AChE. AChE, acetylcholinesterase.
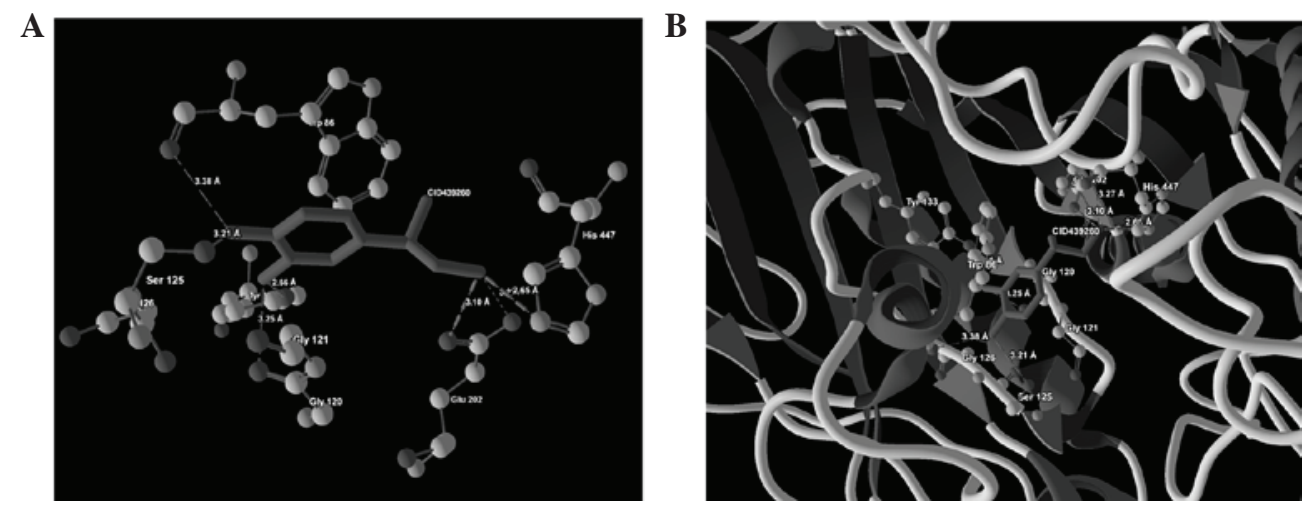

Figure 6. (A) Binding mode of CID439260 at the active site region of AChe enzyme. (B) Secondary structure depicting the strong molecular interactions formed between CID439260 and Gly120, Ser125, Glu202, His447 residues of AChE. AChE, acetylcholinesterase.

top docking hits are presented in Figs. 1-6, and the MD simulation investigating stability of the RMSD backbones of PDB ID: $4 \mathrm{PQE}$ and protein-ligand complexes is demonstrated in Fig. 7.

\section{Discussion}

In the present study, AChE inhibitory assay of the plant extracts demonstrated that the total alkaloidal extracts from Uncaria rhynchophylla (78.4\%), Nelumbo nucifera (76.5\%) and Portulaca oleracea (74.2\%) exhibited AChE inhibition (Table I). In addition, the alkaloidal extract from Areca catechu demonstrated the poorest AChE inhibition (19.3\%; Table I).

Molecular docking analysis of the bioactive compounds present in the herbal plants confirmed that certain compounds in Portulaca oleracea, Zingiber officinale and Camellia sinensis possessed strong molecular interactions at the potential ligand binding site of AChE. The major interactions, including bonded and non-bonded interactions, were formed between the docked compounds and the binding cavity of the enzyme. The strength of the ligand-protein interaction was measured by the Rerank score. The Rerank score is a linear combination of E-inter (steric, Van der Waals, hydrogen bonding, electrostatic) between the ligand and the protein, and E-intra (torsion, sp2-sp2, hydrogen bonding, Van der Waals, electrostatic) of the ligand weighted by

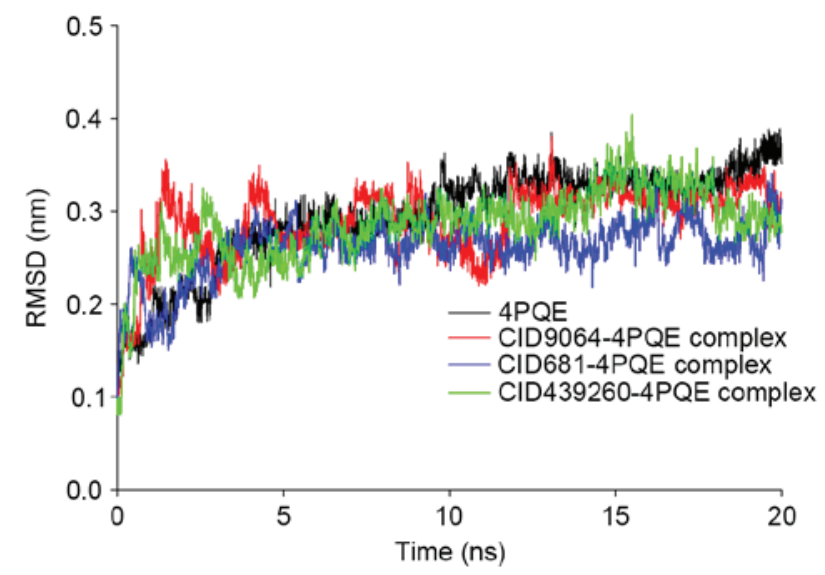

Figure 7. Root mean square deviation (RMSD) backbone of AChE (4PQE), and CID9064-4PQE, CID681-4PQE and CID439260-4PQE complexes.

pre-defined coefficients (24). The Rerank score of the docked compounds along with their MolDock score and interaction energy are shown in Table III. In the present molecular docking simulation analysis, CID9064 (Uncaria rhynchophylla) CID681 (Portulaca oleracea), and CID439260 (Portulaca oleracea) and CID6047 (Portulaca oleracea) docked at the binding cavity having a Rerank score of -67.43 , -64.76 and $-60.40 \mathrm{kJmol}^{-1}$, respectively. Uncaria rhynchophylla and Portulacaoleracea exhibited 78.4 and $74.2 \% \mathrm{AChE}$ 
inhibition, respectively. CID 31211 (Zingiber officinale) demonstrated a Rerank score of -59.39 and exhibited $60.5 \%$ AChE inhibition. Finally, CID65084 (Camellia sinensis) had a Rerank score of -53.40 and exhibited $40.2 \%$ AChE inhibition.

To understand the in-depth molecular interaction of these compounds with AChE, and its binding mechanism, a ligand-protein interaction analysis for the top 6 docking hits was conducted using a ligand energy inspector. The ligand-protein interaction, including the residues present, their interaction distances and energy, and the interacting atoms of the protein and ligand are presented in Table IV. The molecular docking simulation indicated that the top docking poses were demonstrated to be docked into the binding cavity displaying bonded and non-bonded interactions. Images depicting ligand-protein binding are shown in Fig. 1 (CID9064), Fig. 2 (CID681), Fig. 3 (CID6047) and Fig. 4 (CID31211), Fig. 5 (CID65084) and Fig. 6 (CID439260). The backbone RMSD values of the protein and protein-ligand complexes during $20 \mathrm{~ns}$ of MD simulation are presented in Fig. 7, and indicated that the RMSD values for AChE-ligand complexes were more stable suggesting a conformational flexibility and stability in dynamic behavior. Numerous herbal compounds have been demonstrated to have anticancer, anti-microbial and anti-inflammatory potential. However, this is not in case of AChE inhibition. In fact, there are few reports on the investigation of herbal compounds as inhibitors of AChE inhibition (26).

In conclusion, Uncaria rhynchophylla, Nelumbo nucifera and Portulaca oleracea possessed strong AChE inhibition. In addition, the molecular docking simulation analyses demonstrated that the active compounds present in Uncaria rhynchophylla (CID9061) and Portulaca oleracea (CID681 and CID439260) had strong molecular interactions, as evidenced by the molecular docking scores and ligand-protein interaction energy analyses. Furthermore, the MD simulation confirmed the stability of the protein-ligand docked complexes. The results of the present study suggested that CID9064 (catechin), CID681 (dopamine) and CID439260 (norepinephrine) may be key bioactive ingredients that may be prescribed to patients with AD.

\section{Acknowledgements}

The authors would like to acknowledge the 5th People's Hospital of Wuhan (Wuhan, Hubei, P.R. China) for necessary support.

\section{References}

1. Burns A and Iliffe S: Alzheimer's disease. BMJ 338: b158, 2009

2. Querfurth HW and LaFerla FM: Alzheimer's disease. New Eng J Med 362: 329-344, 2010.

3. Todd S, Barr S, Roberts M and Passmore AP: Survival in dementia and predictors of mortality: A review. Int J Geriatr Psychiatry 28: 1109-1124, 2013.
4. Ballard C, Gauthier S, Corbett A, Brayne C, Aarsland D and Jones E: Alzheimer's disease. Lancet 377: 1019-1031, 2011.

5. Thompson CA, Spilsbury K, Hall J, Birks Y, Barnes C and Adamson J: Systematic review of information and support interventions for caregivers of people with dementia. BMC Geriatr 7: $18,2007$.

6. Forbes D, Thiessen EJ, Blake CM, Forbes SC and Forbes S: Exercise programs for people with dementia. Cochrane Database Syst Rev 12: CD006489, 2013.

7. Mendez MF: Early-onset Alzheimer's disease: Nonamnestic subtypes and type 2 AD. Arch Med Res 43: 677-685, 2012.

8. Lozano R, Naghavi M, Foreman K, Lim S, Shibuya K, Aboyans V, Abraham J, Adair T, Aggarwal R, Ahn SY, et al: Global and regional mortality from 235 causes of death for 20 age groups in 1990 and 2010: A systematic analysis for the Global Burden of Disease Study 2010. Lancet 380: 2095-2128, 2012.

9. Berchtold NC and Cotman CW: Evolution in the conceptualization of dementia and Alzheimer's disease: Greco-Roman period to the 1960s. Neurobiol Aging 19: 173-189, 1998.

10. Bonin-Guillaume S, Zekry D, Giacobini E, Gold G and Michel JP: The economical impact of dementia. Presse Med 34: 35-41, 2005 (In French).

11. Meek PD, McKeithan K and Schumock GT: Economic considerations in Alzheimer's disease. Pharmacotherapy 18: 68-73; discussion 79-82, 1998.

12. Francis PT, Palmer AM, Snape $M$ and Wilcock GK: The cholinergic hypothesis of Alzheimer's disease: A review of progress. J Neuro Neurosurg Psychiatry 66: 137-147, 1999.

13. Houghton PJ, Ren YH and Howes MJ: Acetylcholinesterase inhibitors from plants and fungi. Nat Prod Rep 23: 181-199, 2006.

14. Hardy J and Allsop D: Amyloid deposition as the central event in the aetiology of Alzheimer's disease. Trends Pharmacol Sci 12: 383-388, 1991

15. Mudher A and Lovestone S: Alzheimer's disease-do tauists and baptists finally shake hands? Trends Neurosci 25: 22-26, 2002.

16. Quinn DM: Acetylcholinesterase: Enzyme structure, reaction dynamics, and virtual transition states. Chem Rev 87: 955-979, 1987.

17. Taylor P and Radić Z: The cholinesterases: From genes to proteins. Ann Rev Pharmacol Toxicol 34: 281-320, 1994.

18. Sussman JL, Harel M, Frolow F, Oefner C, Goldman A, Toker L and Silman I: Atomic structure of acetylcholinesterase from Torpedo californica: A prototypic acetylcholine-binding protein. Science 253: 872-879, 1991.

19. Radić Z, Gibney G, Kawamoto S, MacPhee-Quigley K, Bongiorno $\mathrm{C}$ and Taylor P: Expression of recombinant acetylcholinesterase in a baculovirus system: Kinetic properties of glutamate 199 mutants. Biochemistry 31:9760-9767, 1992.

20. Whittaker VP: The contribution of drugs and toxins to understanding of cholinergic function. Trends Pharmacol Sci 11: 8-13, 1990.

21. Purves D, Augustine GJ, Fitzpatrick D, Hall WC, LaMantia AS, McNamara JO and White LE (eds): Neuroscience. 4th edition. Sinauer Associates, Sunderland, MA, pp121-122, 2008.

22. Pohanka M: Alpha7 nicotinic acetylcholine receptor is a target in pharmacology and toxicology. Inter J Mol Sci 13: 2219-2238, 2012.

23. Ellman GL, Courtney KD, Andres V Jr and Feather-Stone RM: A new and rapid colorimetric determination of acetylcholinesterase activity. Biochem Pharmacol 7: 88-95, 1961.

24. Thomsen R and Christensen MH: MolDock: A new technique for high-accuracy molecular docking. J Med Chem 49: 3315-3321, 2006.

25. Van Der Spoel D, Lindahl E, Hess B, Groenhof G, Mark AE and Berendsen HJ: GROMACS: Fast, flexible, and free. J Comput Chem 26: 1701-1718, 2005.

26. Lin HQ, Ho MT, Lau LS, Wong KK, Shaw PC, Wan DC: Antiacetylcholinesterase activities of traditional Chinese medicine for treating Alzheimer's disease. Chem Biol Interact 175: 352-354, 2008. 